University of Nebraska - Lincoln

DigitalCommons@University of Nebraska - Lincoln

2000

\title{
Job compensation in the biotechnology core laboratory
}

Debra A. McMillen

University of Oregon

William M. Old

University of Colorado

Janice L. Bleibaum

Roche Bioscience

Charles M. Nicolet

University of Wisconsin

Katheryn R. Resing

University of Colorado

See next page for additional authors

Follow this and additional works at: https://digitalcommons.unl.edu/biochemistrysarath

Part of the Biochemistry, Biophysics, and Structural Biology Commons

McMillen, Debra A.; Old, William M.; Bleibaum, Janice L.; Nicolet, Charles M.; Resing, Katheryn R.; Sarath, Gautam; and Yadav, Satya P., "Job compensation in the biotechnology core laboratory" (2000). Gautam Sarath Publications. 15.

https://digitalcommons.unl.edu/biochemistrysarath/15

This Article is brought to you for free and open access by the Biochemistry, Department of at DigitalCommons@University of Nebraska - Lincoln. It has been accepted for inclusion in Gautam Sarath Publications by an authorized administrator of DigitalCommons@University of Nebraska - Lincoln. 
Authors

Debra A. McMillen, William M. Old, Janice L. Bleibaum, Charles M. Nicolet, Katheryn R. Resing, Gautam Sarath, and Satya P. Yadav 


\title{
Job compensation in the biotechnology core laboratory
}

\author{
Debra A. McMillen,' William M. Old, Janice L. Bleibaum, ${ }^{3}$ Charles M. Nicolet, ${ }^{4}$ Katheryn R. Resing, ${ }^{2}$ \\ Gautam Sarath, ${ }^{5}$ \& Satya P.Yadav ${ }^{6}$
}

' Debra McMillen is chair, ABRF Survey Committee, and is at the Institute of Molecular Biology, University of Oregon, Eugene, OR 97403

${ }^{2}$ William Old and Katheryn Resing are at the University of Colorado, Boulder, CO 80303

${ }^{3}$ Janice Bleibaum is at Roche Bioscience, Palo Alto, CA 94304

${ }^{4}$ Charles Nicolet is at the University of Wisconsin, Madison, WI 53706

${ }^{5}$ Gautam Sarath is at the University of Nebraska-Lincoln, Lincoln, NE 68588

${ }^{6}$ Satya Yadav is at the Cleveland Clinic Foundation Research Institute, Cleveland, OH 44I95

* Corresponding author: Debra A. McMillen, momillen@molbio.uoregon.edu

\begin{abstract}
The results of a poll of core facility professionals by the Association of Biomolecular Resource Facilities (ABRF) Survey Committee.
\end{abstract}

A large part $(50 \%)$ of the membership of the Association of Biomolecular Resource Facilities (ABRF) ${ }^{1}$ is composed of scientists working in core facilities in academic, government, commercial service, and industry settings. These professionals play an important role providing their fellow researchers with services that range from DNA sequence analysis and bioinformatics to N-terminal protein sequence analysis, HPLC, and mass spectrometry.

One unique feature of the ABRF is studies designed to evaluate the quality of their services. The ABRF Survey Committee has largely focused on the physical evaluation of core facilities: throughput, number of instruments, staff size, budget, and the like $2,3,4,5,6$. Recognizing job compensation to be an important element in the professional recognition of resource facility personnel, the survey committee conducted their first survey on job compensation in 19937. In December 1999, the survey committee launched a new compensation survey that queried core facility personnel, both members and nonmembers of the ABRF, on salary, benefits, job satisfaction, and job responsibilities. Although respondents were primarily from the US, Europe, Canada, and Australia were also represented. In this report, comparisons are made between academic, government, and industry settings, $\mathrm{PhD}$ and non-PhD degrees, director and nondirector positions, and gender.

\section{Methods}

The survey was announced in a letter to all ABRF members in mid-December 1999 and consisted of two HTML forms posted on the web; the first form was to be completed by all respondents, the second form only by directors of core facilities. The survey forms can be viewed on the ABRF web site (http:// www.abrf.org/) in the survey committee section under "Research." Reminders for completion of the survey were posted on the ABRF electronic bulletin board and the last data collected January 17, 2000.

Survey data were automatically stored in a relational database. To provide anonymity, data were released to the survey committee members only after removal of identifying marks. Records that did not fit the intended target population (such as an intern with an annual salary of $\$ 3,000$ ) were discarded. Salary entries of " 39 " or " 84 " were assumed to be $\$ 39,000$ or $\$ 84,000$. All salaries reported in foreign currency were converted to American dollars for purposes of comparison. There were 22 part-time respondents reporting a workweek of less than $40 \mathrm{~h}$
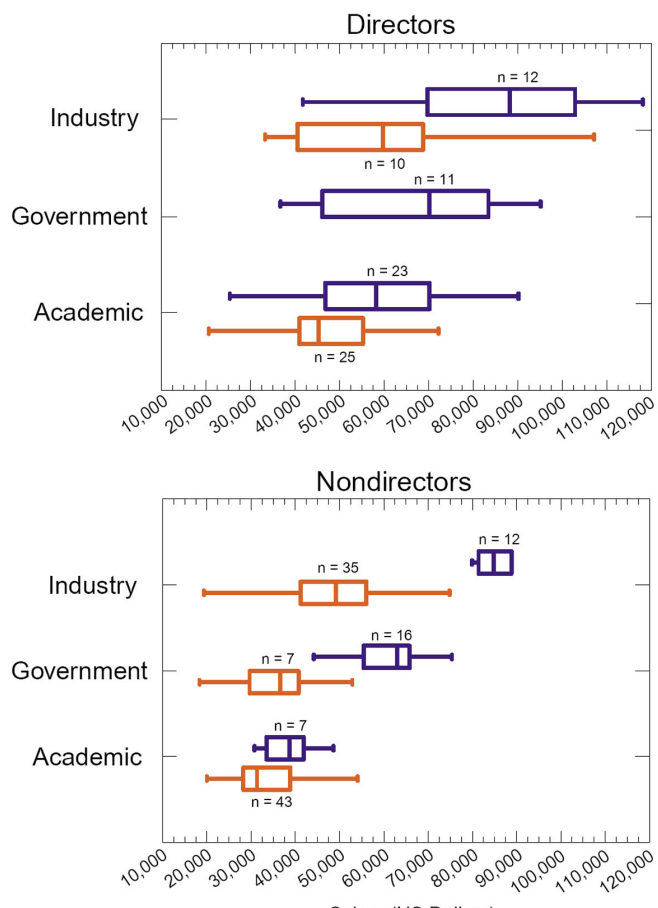

Salary (US Dollars)

Figure I. Salaries for biotechnology core facility personnel. Directors and nondirectors are compared in industry, government, and academic settings. The size of each data set $(n)$ is given; the data set for non-PhD directors in government who responded to this survey was too small to include in the data set $(n<6)$. The data are represented by a box plot with the vertical line in each rectangle representing the median of the entire data set (see Methods). Outliers are present in the data, but are not shown in order to maintain anonymity. Blue, PhD/MD; Red, non-PhD/MD.

(typically, 35 or $37 \mathrm{~h}$ ); these were normalized to a $40 \mathrm{~h}$ salary for comparison with the rest of the database. Data from the entire global population were used in the data analysis, with the nonUS respondents making up a small proportion of the data.

The data were sorted for each subset based on the parameters to be used for comparison. For statistical analysis, only data sets with an $n$ of 6 or greater were compared. Because the data sets are skewed, box plot analyses are used ${ }^{8}$; box plots display the data's dispersion around the median, which is indicated by the vertical line in the box. The 25th to 75th percentiles (H-spread) of the data set values are represented by the box. The horizontal lines (whiskers) that extend to the right 


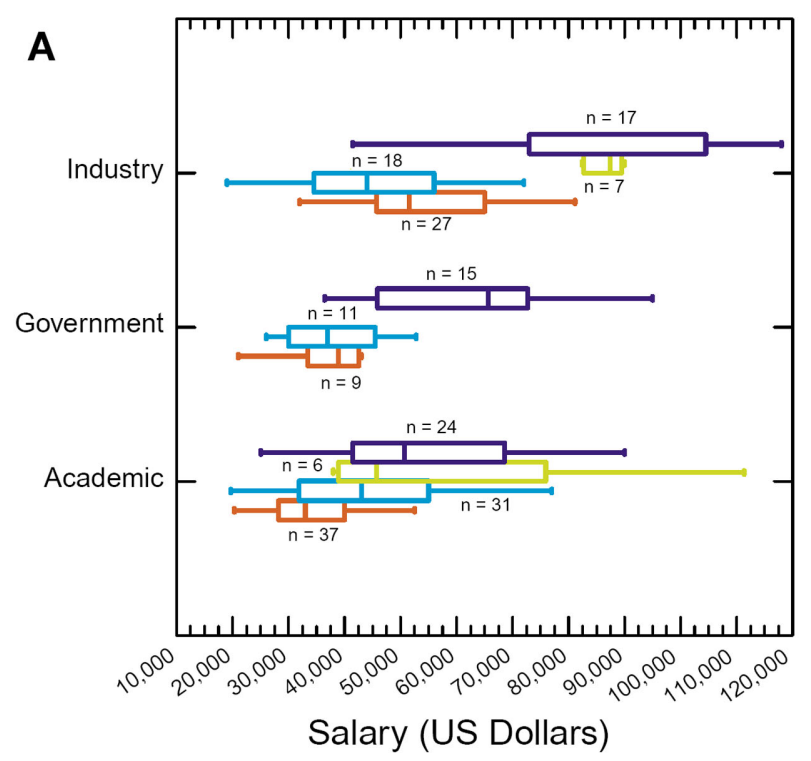

B
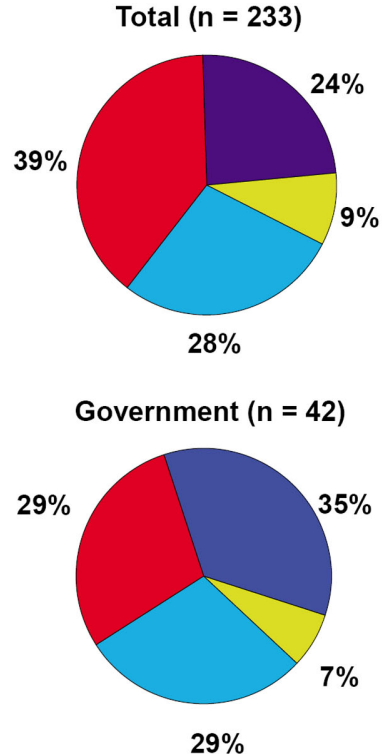
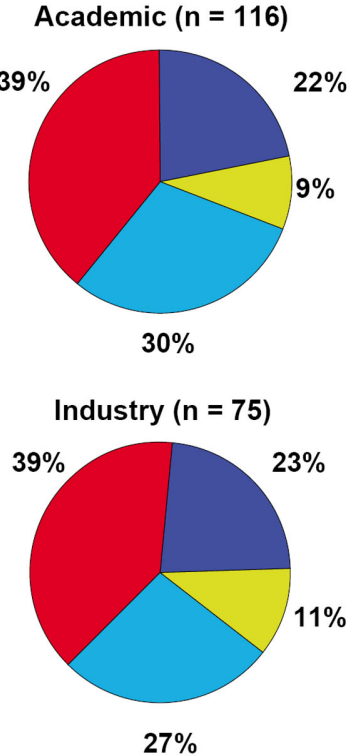

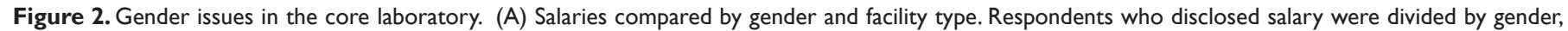

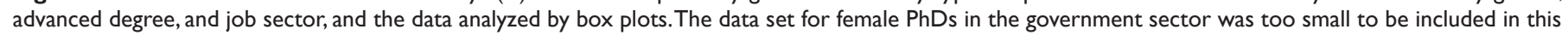

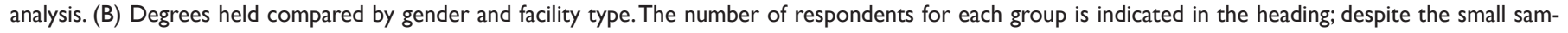

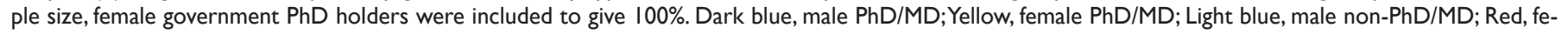
male non-PhD/MD.

and left of the boxes stop at the last data point that is within a distance of 1.5 of the H-spread either above or below the box. Any data point beyond the maximum whisker length is considered an outlier. In this type of analysis, only rectangles that do not overlap are significantly different.

\section{Results and discussion}

Nature of the survey population. Members of ABRF were asked to encourage other professionals in their core facilities, regardless of their ABRF membership, to complete the survey as well. This was done because many resource facilities have only one member in the ABRF, and the salary information for nonmembers is equally important to obtaining a good statistical representation of salaries in the core laboratory. Completed surveys were obtained from 134 ABRF members and 93 nonmembers. The ABRF members consisted of 66 women, $44 \%$ of whom were directors, and 76 men, $59 \%$ of whom were directors. There was no gender difference in median age (42 for men vs. 40.5 for women) or training (16 vs. 15 years in science). Male ABRF members supervised slightly larger numbers of staff, with a median number of staff of two versus a median number of staff of one for women. As expected, the non-ABRF respondents were more heavily skewed toward nondirector positions, with only 16 directors out of 49 men and 6 directors out of 44 women. The non-ABRF respondents supervise fewer staff $(<1)$, and non-ABRF respondents, overall, were slightly younger and less experienced (women, 33 years old with 8 years in science; men, 36 with 10 years in science). These age and training distributions are consistent with the higher proportion of nondirector staff in the non-ABRF respondents.

The 237 respondents were from academic (50\%), industry $(29 \%)$, government $(18 \%)$, and commercial service $(3 \%)$ laboratories. Commercial service laboratory respondents were pooled with industry respondents. Respondents were mainly North American (83\% US, 4\% Canada), with 8\% European, 3\% Australian, and $2 \%$ other. In the US, $33 \%$ were from the northeastern region, $25 \%$ from central, $20 \%$ from the west, $18 \%$ from the southwest, and 13\% from the south. By training, 5\% had less than a bachelor's degree, $41 \%$ a bachelor's, $20 \%$ a master's, and $34 \%$ a doctorate.

\section{Salaries for core facility personnel}

Salaries for directors or nondirectors, with or without higher degrees, were compared for the three sectors (see Figure 1). In most cases, academic and government salaries were comparable for people with similar training and responsibility (directors vs. nondirectors and $\mathrm{PhD}$ vs. non-PhD); as expected, respondents in the industry sector reported significantly higher salaries (40\% for both PhD directors and non-PhD nondirectors). However, for PhD nondirectors the industry respondents reported salaries more than double that of the academic sector, and government salaries were intermediate. There seemed to be a systematic undercompensation of nondirectors with a $\mathrm{PhD}$ in academic core facilities, but their compensation may be in other forms, such as benefits or job security. In academics, there was not a significant difference for salaries of nondirectors whether or not they had a PhD.

Though not shown in Figure 1, a number of respondents were employees paid an hourly wage; this group showed a large percentage increase between 1993, the date of the last survey, and 1999, with an average of $\$ 18.62$ per hour (s.d. = $\$ 8.56)$ in this survey, vs. $\$ 10.31$ per hour (s.d. $=\$ 4.11$ ) in 1993 , an $80 \%$ increase.

\section{Differences in salary based on gender}

A total of 125 males and 110 females responded to the survey (two individuals did not declare their gender). There was no significant difference in gender ratios in the ABRF vs. non$\mathrm{ABRF}$ respondents. An analysis of salaries based on gender and degree is summarized as box plots in Figure 2A.

The overall trends reported in Figure 1 of higher median salaries for industry versus academics and government, and higher salary for more advanced degrees, were evident for 
Table I. Paid holiday, vacation, and sick leave compared by facility type and degree

\begin{tabular}{|c|c|c|c|c|c|c|}
\hline & $\begin{array}{c}\text { Academic } \\
\mathrm{n}\end{array}$ & $\begin{array}{l}\mathrm{PhD} \text { \& non-PhD } \\
\text { Median \& range }\end{array}$ & $\begin{array}{c}\text { Government } \\
\mathrm{n}\end{array}$ & $\begin{array}{l}\mathrm{PhD} \& \text { non-PhD } \\
\text { Median \& range }\end{array}$ & $\begin{array}{c}\text { Industry } \\
\mathrm{n}\end{array}$ & $\begin{array}{l}\mathrm{PhD} \& \text { non-PhD } \\
\text { Median \& range }\end{array}$ \\
\hline Holidays & 103 & 10 days $(0-35)$ & 41 & 10 days $(4-47)$ & 66 & 12 days $(2-30)$ \\
\hline Sick leave & 79 & 12 days $(0-40)$ & 27 & 12 days $(0-40)$ & 30 & 8 days $(0-60)$ \\
\hline
\end{tabular}

Benefits reported by core facility personnel, comparison by facility type and degree

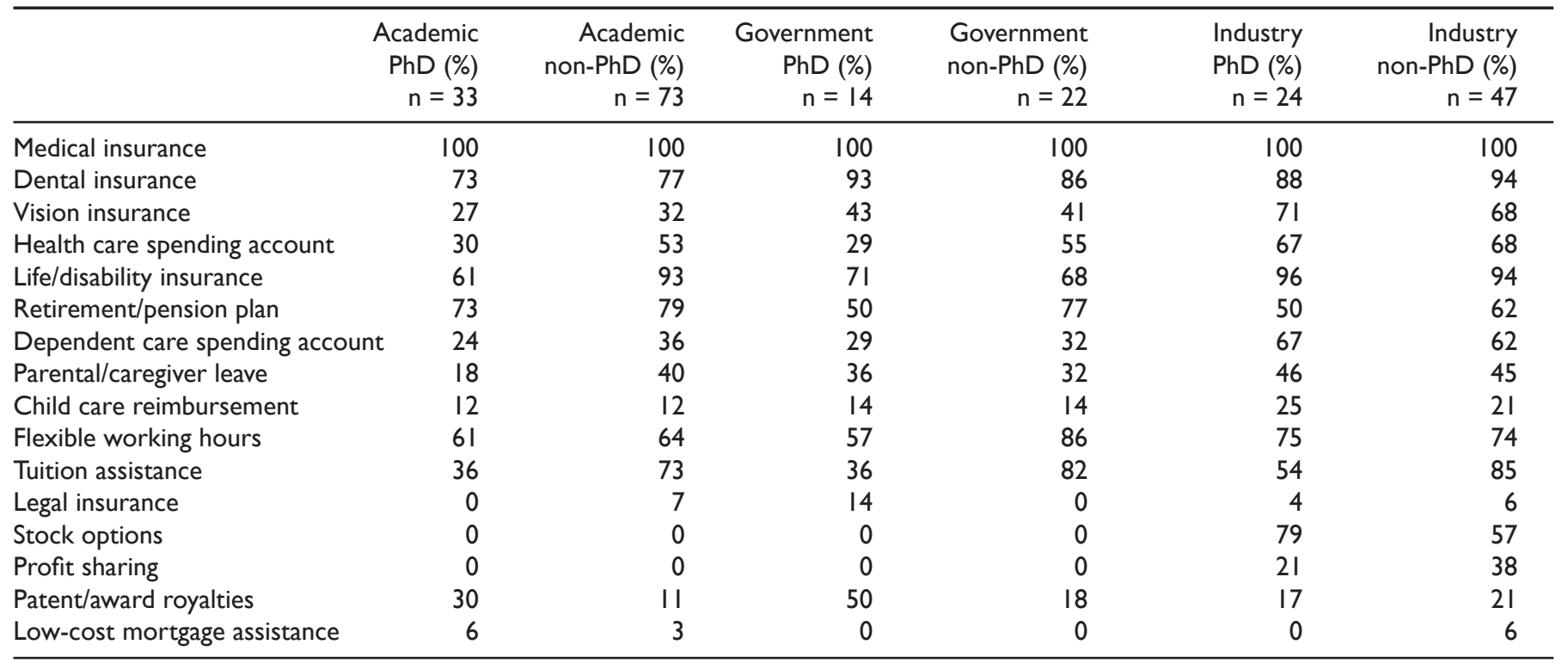

both men and women. However, there are no significant differences between salaries for men and women at the same degree levels whether the labs were academic, industry, or government. This is in contrast to national trends that still show a persistent wage gap between men and women at all educational levels and in all job sectors ${ }^{9}$. A closer look at these subsets revealed no obvious discrepancy that might explain the surprising similarities. For example, both men and women were closely matched by age and by the number of years they had been in their current position in each of the subdivisions.

These salary data are in accord with the findings of the 1993 ABRF compensation survey ${ }^{7}$, which compared gender differences in nonprofit (academic and government) and forprofit (industry and commercial service) facilities. That survey concluded that there was a difference between salaries for men and women directors at for-profit institutions, but that "[n]o other statistically significant differences were found in the levels of compensation between male and female salaries with equivalent positions."

However, there are disparities in the proportion of men and women holding advanced degrees in all three types of core facilities. Figure $2 \mathrm{~B}$ shows the percentages of males and females with or without advanced degrees (PhD or MD) for the entire pool of respondents and for individual facility types. Approximately $48 \%$ of the 233 respondents used in this analysis were women, yet they accounted for only $27 \%$ of the advanced degrees. The same trend was seen in the subdivided pools representing the academic and industry sectors, where women accounted for $48 \%$ of the academic and $50 \%$ of the industry respondents, yet represented only $29 \%$ of the academic and $32 \%$ of the industry PhDs. Fewer respondents in the government sector as a whole were women at $36 \%$, and they made up only $17 \%$ of the government $\mathrm{PhD} / \mathrm{MD}$ pool. The gender differences in the advanced-degree subpopulation are probably not due to an age bias within the pools, because the average age of the male and female respondents is statistically the same in each sector (data not shown).

The finding that women holding doctoral degrees are underrepresented in the workplace matches national trends in the life sciences. For example, in 1997 the National Science Foundation reported approximately $36 \%$ of employed scientists holding at least a bachelor's degree in the life sciences were women, whereas only $28 \%$ of individuals holding doctorates in the workplace were women ${ }^{10}$. This underrepresentation is not a reflection of degrees awarded, because in the last 10 years approximately $37 \%$ of doctorates in the biological sciences have gone to women ${ }^{11}$.

\section{Benefits in the core facility}

Medical coverage, retirement plans, vacation, and sick leave are important parts of job compensation. Table 1 shows the makeup of benefits received by core facility personnel. The top portion lists vacation time, holidays, and sick leave in the three main job sectors. The lower portion lists a variety of other benefits such as medical benefits, insurance, child care, tuition assistance, and stock options, and is also divided by $\mathrm{PhD}$ and non-PhD. Respondents from academic and government sectors on average receive $50 \%$ more sick leave time (12 days) compared to industry (8 days). Similarly, academic and government employees received an average of 21 and 20 days of vacation, respectively, whereas industry has 15 vacation days. On the other hand, respondents from industry received two extra holidays compared to academic and government sectors, bringing industry days off to 17 days. 
All respondents from the three job sectors were fully covered by medical insurance, whereas dental insurance was provided to $77 \%, 86 \%$, and $94 \%$ of academic, industry, and government sectors. Vision insurance differed significantly in the three sectors, with $\sim 70 \%, \sim 42 \%$, and $\sim 30 \%$ in industry, government, and academic sectors, respectively. Health care spending account benefits were similar in the academic and government job sectors, with $30 \%$ for $\mathrm{PhD}$ and $55 \%$ for non-PhD; the industry sector provided $68 \%$ coverage for all staff. Retirement and pension plans were better in the academic and government job sectors than the industry side, which may be compensated by stock options and profit sharing, available only in the industry job sector ( $57 \%$ of industry respondents get stock options, whereas $38 \%$ get a profit-sharing plan). Other benefits, like the dependent care spending account, parental/caregiver leaves, and child care, were better in the industry job sector as compared to the other job sectors. Tuition assistance in all sectors is reported by non-PhDs at a higher level $(30-45 \%)$ higher than by PhDs. Respondents reporting legal insurance were an unusual mix. About $5 \%$ of both PhDs and non-PhDs in industry reported receiving legal insurance, however, in government $14 \%$ of PhDs and none of the non-PhDs receive it. In academia, none of the PhDs, yet 7\% of the non-PhDs reported receiving it. The significance of these differences is somewhat unclear, since lack of a yes response by a respondent can mean either that they do not receive the benefit or that they do not know if they receive it as a benefit.

\section{Job satisfaction in the core facility}

Despite the differences in salary and benefits, core facility personnel in all three sectors showed approximately equivalent job satisfaction. When asked how satisfied they were with their jobs, $50-60 \%$ of the respondents in all facility types stated that they were satisfied with their jobs; $15 \%$ were extremely satisfied with their jobs. Only 2-3\% in each sector were "not satisfied" with their jobs. In direct response to what they liked about their job, no one mentioned salary, but rather cited the work environment: autonomy/independence, flexibility, coworkers and fellow scientists, and intellectual challenge. Only $16 \%$ indicated a desire for a higher salary, whereas $12 \%$ desired more responsibility/more challenging work. Overall, the survey revealed a dedicated professional group whose major concerns were with those things that would facilitate their doing a good job in the long term.

\section{Conclusions}

The job compensation data collected from resource facility professionals in this survey revealed that compensation for core facility personnel essentially reflects expected trends for life science professionals on the whole: compensation was directly correlated with degree, with higher degree holders drawing a significantly greater salary. Also, the industrial sector awarded greater salaries compared to the academic and government settings. One important difference noted in our study is that men and women are remunerated equivalently in the core laboratory, a finding that contrasts with national trends, but is consistent with the 1993 ABRF salary survey. Unfortunately, the "shrinking pipeline" effect was also in evidence, where women holding advanced degrees appeared in fewer numbers in all facility types.
A thorough comparison of these data with those of the 1993 ABRF survey is difficult because of the different nature of the survey population, but some observations can be made. Nondirector salaries have risen about $43 \%$, with nearly identical percentage increases in both academic/government and industry sectors. The average wage for hourly employees has increased $80 \%$. On the other hand, no significant change is apparent in director salaries. One reason for this may be due to the changing size of core facilities. In 1999, smaller labs made up a larger proportion of the surveyed facilities (the average facility surveyed in 1993 had four staff members, whereas the average facility surveyed in 1999 had one or two staff members). Future surveys will assess the effect of this and other possible factors.

\section{Acknowledgments}

The ABRF Survey Committee would like to thank the survey respondents for their time and interest. We would also like to thank William Oliver at the University of Colorado, Boulder, for his helpful discussions on the statistical analysis of the data.

\section{References}

1. Niece, R. L., Williams, K., \& Naeve, C. Professional Societies, Association of Biomolecular Resource Facilities. pp 2089-2120 in Flickinger, M. C. \& Drew, S. W. (eds), Encyclopedia of Bioprocess Technology. (John Wiley \& Sons, New York; 1999).

2. Ivanetich, K. M., Niece, R. L., Rohde, M., Fowler, E., and Hayes, T. K. Biotechnology core facilities: trends and update. FASEB J. 7, 1109-1114 (1993).

3. Niece, R. L., Beach, C. M., Cook, R. F., Hathaway, G. M., and Williams, K. R. State of the art biomolecular core facilities: a comprehensive survey. FASEB J. 5, 2756-2760 (1991). Erratum. FASEB J. 6, 792 (1992).

4. Williams, K. R. et al. The size, operation, and technical capabilities of protein and nucleic acid core facilities. FASEB J. 2, 3124-3130 (1988).

5. Ivanetich, K. M. et al. Biotechnology facility instrumentation survey. Gen. Eng. News 17, 17 (1997).

6. McMillen, D. A. et al. Biotechnology core laboratories: an overview. J. Biomol. Techniques 11, 1-11 (2000).

7. Bibbs, L. et al. Compensation and employment profiles in biotechnology core facilities. ABRF News and Views 7, 1821 (1996).

8. Tukey, J. W. Exploratory data analysis. (Addison-Wesley, Reading, MA; 1988).

9. Data reported through 1996, US Dept. of Labor, Women's Bureau, from http://www.dol.gov/wb

10. NSF Scientists and Engineers Statistical Data system. (1998).

11. Science and Engineering Doctorate Awards: 1998. (NSF, Division of Science Resource Studies, October 1999). 